\title{
ANALISIS PENGARUH CYBER PUBLIC RELATIONS TERHADAP KESADARAN MEREK SEBUAH PERGURUAN TINGGI SWASTA MENGGUNAKAN STUCTURE EQUATION MODELLING (SEM)
}

\author{
Mila Hidayatullah', M.Syukron Anshori ${ }^{2}$, Chairul Hudaya ${ }^{3^{\star}}$ \\ ${ }^{1}$ Program Studi Magister Manajemen Inovasi, Sekolah Pascasarjana Universitas Teknologi Sumbawa \\ Jl. Raya Olat Maras, Batu Alang, Moyo Hulu, Sumbawa, Nusa Tenggara Barat, Indonesia \\ 2Fakultas IImu Komunikasi Univeersitas Teknologi Sumbawa \\ Jl. Raya Olat Maras, Batu Alang, Moyo Hulu, Sumbawa, Nusa Tenggara Barat, Indonesia \\ ${ }^{3}$ Departemen Teknik Elektro, Fakultas Teknik Universitas Indonesia \\ Kampus Baru UI Depok, 16424 Jawa Barat,Indonesia \\ ${ }^{*}$ Corresponding author: mila.hidayatullah@uts.ac.id1 , Muhammad.syukron.anshori@uts.ac.id ${ }^{2}$ \\ c.hudaya@uts.ac.id $\mathbf{3}^{*}$
}

\begin{abstract}
Abstrak
Diterima:

Bulan Januari 2021

Diterbitkan:

Bulan Februari 2021

Keyword : Cyber PR, Brand Awareness, Structur Equation

Penelitian ini difokuskan pada pengaruh aktivitas hubungan masyarakat (Public Relation- $P R)$ melalui penggunaan internet $($ Cyber $P R)$ terhadap kesadaran merek sebuah perguruan tinggi swasta. Tujuan penelitian ini adalah untuk mengetahui bagaimana pengaruh aktivitas cyber $P R$ yang dilakukan oleh Humas Universitas Teknologi Sumbawa (UTS) melalui media sosial seperti Facebook, Youtube dan Instagram terhadap peningkatan kesadaran merek (brand awareness) UTS. Penelitian ini menggunakan metode kuantitatif dengan structural equation modelling (SEM) SPSS untuk menyusun model hasil penelitian. Adapun populasi sampel yang digunakan dalam penelitian ini adalah masyarakat Kecamatan Sumbawa dengan kriteria umur 15-29 tahun dimana 124 responden mengisi kuesioner sebagai representasi dari 16.770 jiwa masyarakat Sumbawa untuk kategori umur tersebut. Dari hasil uji $F$ terdapat pengaruh simultan antara variabel-variabel bebas (variabel Facebook, Instagram dan Youtube) terhadap variabel terikat (Brand Awareness). Sementara dari hasil dari uji $t$ diperoleh bahwa variabel Instagram yang memiliki pengaruh secara signifikan terhadap peningkatan brand awareness kampus UTS.
\end{abstract} Modelling

\section{PENDAHULUAN}

Perkembangan teknologi komunikasi dan informasi saat ini begitu pesat, yang memungkinkan pengguna dengan mudah berkomunikasi dengan publik dimanapun dan kapanpun.Internet sebagai salah satu kemajuan teknologi komunikasi telah banyak merubah pola komunikasi yang ada selama ini. Menurut Cutlip, Center, dan Broom (2007: 287) internet merupakan revolusi komunikasi yang sangat luas dan mendalam. Internet melahirkan media baru seperti media online dan media sosial.

Dari data Statistik 22 Februari 2019 menunjukkan bahwa perkembangan pengguna internet di Indonesia dari tahun ketahun meningkat sangat siginifikan. Dari tahun 2018 meningkat sebanyak 95,2 juta atau tumbuh 13,3\%. Pada tahun selanjutnya pertumbuhan $10,2 \%$ pada periode 2018-2023, dan diproyeksikan pertumbuhan pengguna internet sebesar $12,6 \%$ dibandingkan 2018 yaitu sebanyak 107,2 juta pengguna. Selanjutnya tahun 2023 diperkirakan pengguna internet mencapai 150 juta. Statistik menyebutkan bahwa kegiatan online yang paling populer di
Indonesia kelak adalah media sosial (https://databoks.katadata.co.id/).

Melihat prediksi tersebut bahwa media sosial akan menjadi salah satu media komunikasi yang paling banyak digunakan dalam berinteraksi dan berkomunikasi dengan publik, karena didukung oleh kemudahan penggunaan dan pengelolaan media sosial. Menurut Chris Brogan (2010), media sosial adalah seperangkat alat komunikasi dan kolaborasi baru yang memungkinkan terjadinya berbagai jenis interaksi yang sebelumnya tidak tersedia bagi orang awam. Sedangkan menurut Varinder Taprial dan Priya Kanwar (2012), media sosial adalah media yang digunakan oleh individu agar menjadi sosial, atau menjadi sosial secara daring dengan cara berbagi isi, berita, foto dan lain-lain dengan orang lain.

Saat ini hampir semua aktivitas sehari-hari masyarakat tidak bisa lepas dari media sosial, karena media sosial bisa menembus ruang dan waktu. Fenomena ini memberi kemudahan bagi profesi hubungan masyarakat atau public relations (PR) untuk menjalankan fungsi PR dalam upaya meningkatkan branding dan trust kepada publik, maka media sosial adalah salah satu media yang 
pas saat ini yang digunakan oleh seorang PR. Segala aktivitas public relations dengan menggunakan internet disebut cyber public relations (cyber $P R$ ), Dengan cyber $P R$ dalam penyampaian pesan kepada target publik akan lebih mudah, serta memanfaatkan potensi-potensi besar lainya (Onggo, 2004).

Populernya media sosial ini menjadi tantangan bagi PR dalam menjalankan fungsi kehumasan yang lebih interaktif dengan jangkauan yang lebih luas dan penetrasi informasi seketika. Martin Lister dkk dalam bukunya New Media: A Critical Introduction (2009 : 13) menyatakan bahwa terminologi media baru mengacu pada perubahan skala besar dalam produksi media, distribusi media dan penggunaan media yang berifat teknologis, tekstual, konvensional dan budaya. Perubahann yang signifikan ini, harus direspon dengan baik, karena perubahan yang terjadi tidak hanya dari sisi media namun juga perubahan terjadi pada minat dan ketertarikan audience yang semakin bervariasi.Maka aktivitas Cyiber public relations harus digunakan dan dimanfaatkan dengan maksimal melalui media sosial, agar informasi dan pesan sampai dengan baik kepada publik.

Cyber $P R$ menjadi kegiatan yang populer dikalangan PR dan banyak digunakan oleh perusahaan dan institusi pendidikan guna untuk melakukan engagement dengan publiknya. Cyber $P R$ dilakukan sebagai bentuk meminamalisir kendala atau hambatan dalam berkomuniaksi, juga cyber $P R$ sebagai media promosi yang sangat efektif karena bisa menembus ruang dan waktu serta menimbulkan komunikasi dua arah, hal tersebut tidak bisa dilakukan langsung oleh media seperti televisi dan surat kabar.

Fenomena ini pun menjadi tantangan besar bagi perguruan tinggi swasta, dalam hal ini Humas Universitas Teknologi Sumbawa (UTS) dalam menghadapi era revolusi industri 4.0, untuk menjalankan fungsi kehumasan dengan berinovasi mengikuti tren yang ada agar bisa mencapai tujuan dan visi misi UTS. Suatu keharusan bagi UTS untuk melakukan inovasi dan adaptasi, karena inovasi selalu menjadi poin interest bagi banyak orang untuk bertarung dan bertahan, sesuai dengan ungkpan populer "Innovate or Die", dalam pertarungan dan pertahanan hanya ada dua pilihan inovasi atau mati.

Salah satu bentuk aktivitas $C y b e r P R$ yang dilakukan oleh humas UTS adalah telah menggunakan media sosial Facebook dengan akun"Universitas Teknologi Sumbawa", Instagram @universitasteknologisumbawa dan Youtube : Universitas Teknologi Sumbawa sejak tahun 2016. Penelitian ini dilakukan untuk mengetahui status dan kondisi seberapa signifikan dan seberapa pengaruh usaha Cyber $P R$ yang telah dilakukan oleh Humas UTS terhadap peningkatan brand awareness dari masyarakat, khususnya masyarakat Kecamatan Sumbawa dengan rentang usia 15-29 tahun.

\section{LANDASAN TEORI}

\section{Definisi Cyber PR}

Cyber $P R$ atau E-PR menurut Onggo (2004:7), adalah inisiatif PR yang menggunakan media internet sebagai sarana publisitas. Masih menurut Onggo (2004:4), kegiatan cyber PR dapat menghasilkan apa yang disebut 3R bagi organisasi/perusahaan : (1) Relations, yaitu dapat berinteraksi dengan berbagai target audience guna membangun hubungan dan citra perushaan, (2) Reputasi, yaitu aset paling penting dalam bisnis, EPR adalah seni membangun reputasi online secara berkesinambungan; dan (3) Relevansi, yaitu mengupayakan kegiatan inisiatif PR secara online dapat relevan dengan publik korporat.

\section{Efektivitas Cyber Public Relations}

Efektivitas secara umum adalah seberapa jauh tujuan-tujuan yang telah ditentukan itu bisa tercapai sesuai dengan terget yang diinginkan. Menurut Hidayat (1986) bawah Efektifvtas adalah suatu ukuran yang menyatakan seberapa jauh target (kuantitas,kualitas dan waktu) telah tercapai. Karena jika makin besar presentase target yang akan dicapai, maka makin tinggi pula efektivitasnya.

Menurut Emerson (dalam Hasibuan 2014) efektivitas adalah pengukuran dari tercapainya sasaran atau tujuan yang telah ditentukan sbelumnya. Agar aktivitas Cyber $P R$ berjalan dengan lancar, terdapat elemen dasar yang harus diperhatikan oleh PR, seperti yang dijelaskan oleh Phillips \& Young (2009:37) yaitu transparancy, porosity, the internet as agent, richness in content, and reach. Dalam aktivitas Cyber $P R$, transparansi (transparency) informasi perlu disampaikan kepada publik.Sementara internet porositydapat diartikan sebagai transparansi yang tidak disengaja, karena komunikasi dilakukan oleh banyak perusahaan mengunakan internet seperti email, instant messaging, blogs dan media sosial. Banyak informasi yang sampaikan ke publik yang seharusnya tidak bocor namun karena aksesnya yang mudah memungkinkan hal tersebut bisa terjadi.

The Internet as an Agent memperlihatkan ketika sebuah pesan melewati proses perubahan di dunia maya di mana fenomena ini hal yang lumrah terjadi dengan tujuan untuk menyederhanakan pesan dan memberi pemahaman lebih kepada publik. Phillips and Young (2009) mengatakan bahwa 'agency 'adalah proses transformasi pesan dimana pesan tersebut diberikan dari satu orang ke orang lain secara online, dan kemudian memberikan konteks pemahaman baru. Sementara untuk Richness in Content and Reach, Phillips and 
Young (2009:55) menjelaskan kekayaan informasi merupakan proses transparansi yang dieksekusi. Kekayaan informasi banyak disediakan oleh perusahaan, perorangan, teknologi internet dankomputer sebagai agennya. Dalam aktivitas Cyber PR, perlu dilakukan penciptaan konten yang kaya, yang berarti penciptaan konten yang beragam baik penggunaan kata-kata, gambar suara, video, diagram, mikroblog, musik dan lain-lain.Selain itu perlu juga terdapat keterlibatan komunitaskomunitas secara online yang dapat menambah kekayaan informasi.

\section{Media Sosial}

Media sosial seolah menjadi pintu ajaib, karena apapun yang kita cari ada dimedia sosial, dan media sosial sebagai media bagi publik bisa turut berpartisipasi dalam membuat konten, memberikan komentar dan menyebarkannya. Menurut B.K. Lewis (2010), media sosial adalah label bagi teknologi digital yang memungkinkan orang untuk berhubungan, berinteraksi, memproduksi, dan berbagi isi pesan. Sementara menurut Varinder Taprial dan Priya Kanwar (2012), media sosial adalah media yang digunakan oleh individu agar menjadi sosial, atau menjadi sosial secara daring dengan cara berbagi isi, berita, foto dan lain-lain dengan orang lain. Dalam penelitian ini, tiga media sosial menjadi fokus utama yaitu Facebook, Instagram dan Youtube.

\section{Facebook}

Salah satu media sosial yang sudah akrab digunakan oleh masyarakat adalah Facebook. Kepopuleran Facebook menjadikan media online untuk berinteraksi dan berkomunikasi dengan orang lain dari berbagai tempat dan tidak mengenal waktu. Jika dilihat dari beberapa branding yang kerap hadir dihalaman Facebook bahwa Facebook bisa menghubungkan orang-orang yang berada jauh dibelahan dunia. Menurut Hanafi (2016), Facebook adalah website jaringan sosial dimana para pengguna dapat bergabung dalam komunitas seperti kota, kerja, sekolah, dan daerah untuk melakukan hubungan dan berinteraksi dengan orang lain.

Mark Zuckerberg menulis tentang facebook, yaitu: "Facebook's mission is to give people the power to share and make the world more open and connected. In the last four years, we've built new products that help people share more, such as photos, videos, groups, events, wall posts, status updates, and soon." (Misi Facebook adalah memberi orang kekuatan untuk berbagi dan membuat dunia lebih terbuka dan terhubung. Empat tahun yang lalu, kami membangun produkproduk baru yang menolong orang lebih berbagi, seperti foto-foto, video-video, peristiwa - peristiwa, menulis pesan di dinding Facebook, meng-update status, dan seterusnya.) Jadi "power share" adalah misi Facebook, sehingga semua orang yang terkoneksi di facebook bisasaling berbagi dan berinteraksi satu sama lain.

\section{Instagram}

Tidak jauh berbeda dengan Facebook, bahwa Instagram salah satu media sosial yang bisa menghubungkan dan mempertemukan antar individu secara online.

Menurut Jenn Herman (2014) instagram adalah: "Instagram is a photo and video sharing social media site. It was designed for mobile use with the intention that users would take photos on their mobile devices then upload the images , instantly" through instagram app." Instagram merupakan tempat untuk berbagi foto dan video. Instagram dirancang dan dikhususkan pada pengguna samartphone, dengan tujuan agar pengguna instagram dapat mengambil foto atau video secara mudah, kemudian menggunakan sentuhan berbagai filter yang telah disediakan secara instan memposting ke akun instagram yang dimiliki.

\section{Youtube}

Youtube merupakan sebuah situs yang secara khusus menawarkan layanan video sharing (Laksmana Media, 2009) Pada dasarnya, Youtube merupakan sebuah website yang memfasilitasi penggunanya untuk berbagi video yang mereka miliki, atau sebatas menikmati berbagai video klip yang diunggah oleh berbagai pihak (Nesabamedia). Situs yang memiliki slogan "Broadcast Yourself" ini berusaha menciptakan image sebagai situs multimedia, dimana pengunjungnya bisa menikmati sajian-sajian video dengan beragam jenis tema dan kategori (Laksmana Media,2009). Setiap pengunjung diberi kebebasan untuk mengambil video secara free dengan cara mendownload, serta bebas membagi semua video yang ada di Youtube.

\section{Kesadaran Merek (Brand Awareness)}

Berdasarkan keterangan dari Investopedia (22/4/2019), idealnya kesadaran merek itu dapat mencakup kualitas yang membedakan produk dari para pesaingnya. Kesadaran merek mencakup asset - asset terpenting bisnis, yang terdiri dari asset tak berwujud, nama perusahaan, merek, simbol, slogan dan asosiasinya,persepsi kualitas,kepedulian merek, basis pelanggan, serta sumber daya seperti hak paten, trademark, dan hubungan dengan dealer, yangsemuanya merupakan sumberutama keunggulan bersaing dan pendapatan di masa depan (Hermawan, 2012:57).

Durianto,dkk (2004) menjelaskan bahw tingkatan dalam brand awareness dapat digambarkan sebagai sebuah piramida. Tingkat terendah sampai tingkat tertinggi adalah sebagai berikut: Unaware of brand, adalah tingkatan paling 
rendah karena pada tingkatan ini konsumen tidak menyadari adanya merek. Brand recognition, yaitu keadaan dimana konsumen telah mengenal suatu merek yang munculsetelahdilakukan pengingatan kembali lewat sebuah bantuan. Brand recallatau pengingatankembali terhadap merektanpa menggunakan bantuan.Top of mind(puncak pikiran), yaitu tingkatan kesadaran merek dimana konsumen menyebut merek tertentu atau pertama kali ada di benak konsumen. Dengan kata lain merek tersebut merupakan merek utama dari berbagai merek yang ada di dalam benak konsumen.

Kesadaranmerekadalahkemampuan

sebuah merek untuk muncul dalam benak konsumen ketika mereka sedang memikirkan kategori produk tertentu dan seberapa mudahnya nama tersebut muncul (Shimp, 2003).

\section{METODE PENELITIAN}

Jenis penelitian ini menggunakan metode penilitian kuantitatif yang meliputi pengumpulan data untuk menguji hipotesis atau menjawab pertanyaan-pertanyaan. Tipe yang paling umum digunakan oleh metodologi deskriptif adalah sikap, pendapat individu, organisasi, keadaan ataupun prosedur yang dikumpulkan melalui daftar pertanyaan dalam survei, wawancara ataupu observasi (Kuncoro: 2013 : 12). Peneilitian ini bertujuan untuk mengetahui seberapa besar pengaruh media sosial Facebook, Instagram dan Youtube terhadap kesadaran merek dari UTS yang dilakukan oleh tim Humas UTS.

Responden penelitian ini berasal dari Kecamatan Sumbawa, dengan rentang umur responden 15-29 tahun dan total responden sebanyak 124 responden. Jumlah responden ini melebihi nilai responden menurut Slovin, dimana jumlah masyarakat Kecamatan Sumbawa pada rentang umur tersebut sebanyak 16.770 orang.

$$
n=\frac{16.770}{1+\left(16.770 \times 0,1^{2)}\right.}=99,4
$$

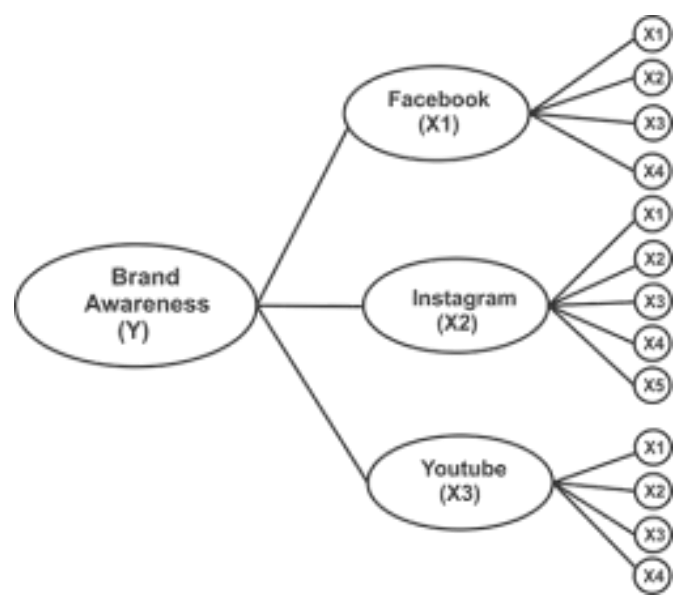

Gambar. 1.

\section{Konsep SEM dalam Menghubungkan Varaibel dengan Variabel Bebas}

Gambar 1 memperlihatkan keterhubungan antara variabel terikat Brand Awareness (Y) dengan variabel bebas Facebook (X1), Instagram (X2) dan Youtube (X3). Dengan menggunakan analisisstructure equation modelling (SEM) menggunakan LISREL akan ditentukan indikatorindikator dan variabel yang mempengaruhi variabel Brand Awareness(Y).

Adapun hipotesis yang digunakan dalam penelitian ini dalam pengolahan data menggunakan SEM adalah sebagai berikut :

1) $H_{01}$ : terdapat hubungan signifikan antara variabel Facebook terhadap brand awareness Universitas Teknologi Sumbawa

2) $\mathrm{H}_{\mathrm{a} 1}$ : terdapat hubungan tidak signifikan antara variabel Facebook terhadap brand awareness Universitas Teknologi Sumbawa

3) $\mathrm{H}_{02}$ : terdapat hubungan signifikan antara variabel Instagram terhadap brand awareness Universitas Teknologi Sumbawa

4) $\mathrm{H}_{\mathrm{a} 2}$ : terdapat hubungan tidak signifikan antara variabel Instagram terhadap brand awareness Universitas Teknologi Sumbawa

5) $\mathrm{H}_{03}$ : terdapat hubungan signifikan antara variabel Youtube terhadap brand awareness Universitas Teknologi Sumbawa

6) $\mathrm{H}_{\mathrm{a} 3}$ : terdapat hubungan tidak signifikan antara variabel Youtube terhadap brand awareness Universitas Teknologi Sumbawa

\section{HASIL DAN PEMBAHASAN \\ Hasil Uji Validitas dan Reliabilita \\ a) Uji Validitas}

Setelah melalui analisis SEM, seluruh variabel Brand Awareness (Y) yang terdiri dari Y1, Y2, Y3 dan Y4 menghasilkan nilai rhitung > rtabel.

- Variabel Facebook (X1) yang terdiri dari $\mathrm{X} 1.1, \mathrm{X} 1.2$, X1.3, dan X1.4 semuanya menghasilkan nilai rhitung $>$ rtabel

- Variable Instagram (X2) yang terdiri dari $\mathrm{X} 2.1, \mathrm{X} 2.2, \mathrm{X} 2.3, \mathrm{X} 2.4, \mathrm{X} 2.5$, dan X2.6 semuanya menghasilkan nilai rhitung > rtabel

- Variabel Youtube (X3) yang terdiri dari $\mathrm{X} 3.1, \mathrm{X} 3.2$, X3.3, dan X3.4 semuanya menghasilkan nilai rhitung > rtabel

\section{b) Uji Reliabilitas}

Dari hasil uji reliabilitas menggunakan SPSS diperoleh masing-masing variabel nilai Cronbach's alpha $>0,5$ yang berarti bahwa semua intrumen dalam penelitian ini reliabel.

\section{Uji Asumsi Klasik}

a) Uji Normalitas 
Berdasarkan hasil uji normalitas Kolomogrov Smirnov menggunakan SPSS diperoleh hasil signifikasi dari uji normalitas sebesar 0,274 dimana hasil tersebut lebih besar dari taraf signifikasi 0,05. Sehingga dapat disimpulkan bahwa uji tes normalitas pada penelitian ini adalah berdistribusi normal.

\section{b) Uji Multikolinearitas}

Dari hasil perhitungan menggunakan SPSS diperoleh bahwa nilai VIF setiap variabel kurang dari 10. Maka dapat disimpulkan data penelitian bebas dari multikolinearitas.

\section{c) Uji Heterokedasitas}

Berdasarkan hasil uji heterokedasitas menggunakan SPSS diperoleh hasil signifikasi variabel X1, X2, X3 lebih besar dari 0,05. Maka dapat disimpulkan bahwa data penelitian tidak terjadi masalah heterokedasitas.

\section{d) Uji Autokorelasi}

Berdasarkan hasil tabel uji autokorelasi diperoleh nilai Durbin-Waston $(\mathrm{DW})=1,733$. Selanjutnya dibandingkan dengan nilai table signifikasi 0,05 dengan jumlah sampel 124 dan jumlah variabel independen $=3(\mathrm{~K}=3)$ sehingga diperoleh hasil dU dari table $=1,7567$. Jadi nilai DW lebih kecil dari $(4-d U)=4-1,7567=2,2433$. Maka dapat disimpulkan data penelitian tidak terdapat autokorelasi.

\section{1) Uji F}

Berdasarkan uji $F$ menggunakan SPSS diperoleh $F_{\text {hitung }}=4,532$ sedangkan $F_{\text {tabel }}=3,07$ karena nilai $F_{\text {hitung }}$ lebih besar dari $F_{\text {tabel }}$ maka terdapat pengaruh simultan antara variabel-variabel bebas (variabel Facebook, Iinstagram dan Youtube) terhadap variabel terikat (Brand Awareness).

Tabel 1.

\section{Uji Hipotesis}

\begin{tabular}{|c|c|c|c|c|}
\hline \\
\hline Hipotesis & Path & t-value & Estimasi & Hasil \\
\hline $\mathrm{H}_{01}$ & $\begin{array}{l}\text { Facebook } \mathrm{Br} \\
\text { and } \\
\text { Awareness }\end{array}$ & 0,83 & 0,24 & Ditolak \\
\hline $\mathbf{H}_{02}$ & $\begin{array}{l}\text { Instagram } B \\
\text { rand } \\
\text { Awareness }\end{array}$ & 1,43 & 0,51 & Ditolak \\
\hline $\mathbf{H}_{03}$ & $\begin{array}{l}\text { Youtube } \mathrm{Br} \\
\text { and } \\
\text { Awareness }\end{array}$ & 1,82 & 0,38 & Ditolak \\
\hline
\end{tabular}

Selanjutnya dilakukan uji hipotesis untuk menentukan apakah terdapat hubungan yang signifikan antara variabel terikat dengan varabel bebas. Hipotesis pertama $\left(\mathrm{H}_{01}\right)$ dilakukan untuk Variable Facebook (X1). Berdasarkan hasil analisis dan perhitungan menggunakan metode SEM SPSS, sesuai dengan Tabel 1memberikan hasil hipotesis ditolak karena t-value sebesar 0,83 (tingkat keyakinan 95\%) < 1,96 yang berarti terdapat hubungan tidak signifikan antara variabel Facebook terhadap brand awareness Universitas Teknologi Sumbawa. Nilai estimasi yang ditunjukan pada tabel yaitu sebesar 0,24 menandakan bahwa pengaruh variabel facebook berpengaruh positif dan tidak secara signifikan terhadap brand awareness Universitas Teknologi Sumbawa.

Variabel Instagram (X2) dilakukan Hipotesis $02 \quad\left(\mathrm{H}_{02}\right)$ sepertiterlihat dari Tabel 1 ditolak karena t-value sebesar 1,43 (tingkat keyakinan 95\%) < 1,96 yang berarti terdapat hubungan tidak signifikan antara variabel Instagram terhadap brand awareness Universitas Teknologi Sumbawa. Nilai estimasi yang ditunjukan pada tabel yaitu sebesar 0,51 menandakan bahwa pengaruh variabel instagram berpengaruh positif dan tidak secara signifikan terhadap brand Awareness Universitas Teknologi Sumbawa.

Selanjurnya hipotesis untuk variable Youtube (X3)yaitu $\mathrm{H}_{03}$ dapat dilihat dari Tabel 1 terbukti ditolak karena t-value sebesar 1,82 (tingkat keyakinan 95\%) < 1,96 yang berarti terdapat hubungan tidak signifikan antara variabel Youtube terhadap brand awareness Universitas Teknologi Sumbawa. Nilai estimasi yang ditunjukan pada tabel yaitu sebesar 0,38 menandakan bahwa pengaruh variabel instagram berpengaruh positif dan tidak secara signifikan terhadap brand awareness Universitas Teknologi Sumbawa.

\section{PENUTUP \\ Kesimpulan}

Berdasarkan hasil analisis menggunakan metode SEM, dapat disimpulkan mengenai pengaruh aktivitas cyber $P R$ terhadap brand awareness perguruantinggi swasta sebagai berikut:

1) Efektivitas cyber $P R$ terhadap kesadaran merek UTS dapat dilihat dari nilai R2 = 0,97yang berarti bahwa tingkat kepercayaan model yang dibentuk dalam penelitian ini yangdipengaruhi oleh Facebook, Instagram dan Youtube adalah sebesar 97\%, sedangkan sisanya $3 \%$ dipengaruhi oleh factor-faktor yang lain yang tidak dijadikan variabel factor dalam penelitian ini.

2) Untuk variabel Facebook memberikan nilai tvalue sebesar $0,83<1,96$ (t-tabel) yang berarti terdapat hubungan tidak signifikan antara variabel Facebook terhadap brand awarenessUTS.

3) Untuk variabel Instagram diperoleh nilai tvalue sebesar $1,43<1,96$ (t-tabel) yang berarti terdapat hubungan tidak signifikan antara variabel Instagram terhadap brand awarenessUTS.

4) Sedangkan variabel Youtube diperoleh nilai tvalue sebesar $1,82<1,96$ (t-tabel) yang berarti terdapat hubungan tidak signifikan 
antara variabel youtube terhadap brand awarenessUTS.

5) Dari hasil analisis dapat dikorelasikan persamaan Brand Awareness (Y)=0,24 Facebook $(\mathrm{X} 1)+0,51$ Instagram $(\mathrm{X} 2)+0,38$ Youtube (X3).Maka model pengaruh media sosial terhadap brand awarenessUTS adalah variabel Instagram yang paling besar pengaruh dibanding dengan Facebook dan Youtube

\section{REFERENSI}

Onggo, Bob Julius (2004) Cyber Public Relations, Strategi Membangun dan Mempertahankan Merk Global di Era Glonalisasi Lewat Media Online. Jakarta: Gramedia

Dominikus,Juju dan Feri,Sulianti (2010) Hitam Putih Facebook. Jakarta: PT Elex Media Komputindo

Herman, Jenn. (2014). The Ultimate Beginners Guide to Instagram. (e-book)

Koordinator Statistik Kecamatan Sumbawa (2019) Kecamatan Sumbawa Dalam Angka. Sumbawa: BPS Kabupaten Sumbawa

Santoso, Singgih. Riadi, Edi (2016) Statistik SEM Structral Equation Modelling dengan LISREL. Jakarta : Penerbit andi2016

Santoso, Singgih (2016) Panduan Lengkap SPSS Versi 23. Jakarta: Elex Media Komputindo

Kusumaningtyas, Ratih Dwi (2010) Peran Media Sosial Online (Facebook) Sebagai Saluran Self Disclosure. Surabaya: Remaja Putri

Arysad, Azhar (2009) Media Pembelajaran. Jakarta: Rajawali

Duarianto, Darmadi, Suagarto, Sinjak, Tony (2004) Strategi Menaklukkan Pasar, Melalui Riset Ekuitas dan Perilaku Merek. Jakarta: PT. Gramedia Pustaka Utama

Santoso, Singgih (2017) Menguasai Statistik dengan SPSS 24. Jakarta: PT. Elex Media Komputindo

Iriantara, Dr. Yosral (2019) Media Realations, konsep, pendekatan, dan praktik. Bandung: simbiosa Rekatama Media

Tjipto, Fandy (2019) Strategi Pemasaran, Prinsip \& Penerapan.Yogyakarta:ANDI
Wijanarko, Susanto Himawan (2004) Power Branding Membangun Merek Unggul \&Organisasi Pendukungnya. Jakarta: PT. Mizan

Shimp, A. Terence (2003) Periklanan Promosi Aspek Tambahan Komunikasi Pemasaran Terpadu. Jakarta: Erlangga

Riyanto. S \& Hatmawan. A.A. (2020). Metode Riset Penelitian Kuantitatif Penelitian Di Bidang Manajemen, Teknik, Pendidikan dan Eksperimen. Yogyakarta: DeePublish CV Budi Utama

Badan Pusat Statistik Kabupaten Sumbawa (2020) Kabupaten Sumbawa dalam angka. Sumbawa: UD. Sari Rejeki

\section{Sumber Pustaka Artikel Jurnal}

Fanny Fibriyanti Salim \& Diah Dharmayanti, S.E., M.Si (2014) "Pengaruh BrandImage dan Perceived Quality Terhadap Kepuasan dan Loyalitas Pelanggan Mobil Toyota di Surabaya”. Jurnal Manajemen Pemasaran Petra Vol. 2, No. 1. Akses tanggal 8 Juli 2020

Dra. Sapmaya Wulan, M.S. (2016) Pengaruh Media Sosial Terahadap Brand Equity Universitas Bandar Lampung

Abdul Basit \& Tri Herni Rahmawati (2017) Cyber Public Relation (E-PR) dalam Brand Image Wardah Kosmetik dengan Pendekatan Mixed Metho. Journal of Communication (Nyimak), Vol.

Muhammad Hanafi, Pengaruh Penggunaan Media Sosial Faceboook Terhadap Motivasi Belajar Siswa FISIP Universitas Riau, Jurnal: JOM FISIP Vol. 3 No. 2 - Oktober 2016, h. 3.

\section{Internet}

http://www.pendidikanekonomi.com/2013/05/defin isi-dan-pengertian-structural.html

http://www.jonathansarwono.info/sem/sem.htm https://databoks.katadata.co.id/datapublish/2018/02 /01/media-sosial-apa-yang-paling-seringdigunakan-masyarakat-indonesia 